\title{
Períodos de Interferência das Plantas Daninhas na Cultura de Cebola (Allium cepa) Transplantada ${ }^{1}$
}

\author{
Periods of Weed Interference With Transplanted Onion Crop (Allium cepa) \\ SOARES, D.J. ${ }^{2}$, PITELLI, R.A. ${ }^{3}$, BRAZ, L.T. ${ }^{4}$, GRAVENA, R. ${ }^{5}$ e TOLEDO, R.E.B. ${ }^{6}$
}

\begin{abstract}
RESUMO - O trabalho foi realizado com o objetivo de estudar os efeitos de períodos de convivência $(0,14,28,42,56,70,84$ e 98 dias após o transplantio) de uma comunidade de plantas daninhas sobre a produtividade de quatro cultivares de cebola (Mercedes, Granex 33, Superex e Serrana), em sistema de transplantio de mudas. O experimento foi instalado em Jaboticabal-SP, de abril a outubro de 2000, utilizando delineamento experimental de blocos ao acaso, quatro repetições, em esquema fatorial 4 x 8 . As principais populações de plantas daninhas no final dos períodos de convivência foram de Coronopus didymus, Amaranthus hybridus e Cyperus rotundus. Os cultivares Mercedes (2,90 kgm-2) e Granex 33 $\left(2,64 \mathrm{kgm}^{-2}\right)$ foram os mais produtivos, independentemente da interferência das plantas daninhas. A convivência com as plantas daninhas durante os primeiros 98 dias reduziu a produtividade da cebola em 95\% e o peso médio de bulbos em $91 \%$. O período anterior à interferência (PAI) foi de 42 dias, não havendo diferença entre os cultivares de cebola.
\end{abstract}

Palavras-chave: comunidade infestante, cultivares.

ABSTRACT - This research was carried out to evaluate the effects of weed coexistence periods $(0,14,28,42,56,70,84$ and 98 days after transplanting) on the productivity of four onion cultivars (Mercedez, Granex 33, Superex and Serrana). The experiment was installed in Jaboticabal - SP - Brazil, from April to October 2000, arranged in a randomized complete block design, with four replications, in a factorial design $4 \times 8$. The main weed populations at the end of the coexistence periods were Coronopus didymus, Amaranthus hybridus and Cyperus rotundus. The cultivars Mercedez $\left(2.90 \mathrm{~kg} \mathrm{~m}^{-2}\right)$ and Granex-33 (2.64 $\left.\mathrm{kg} \mathrm{m}^{-2}\right)$ were the most productive, under the conditions of weed interference. Weed interference during the first 98 days reduced production weight around 95\% and the average weight of bulbs was reduced by 91\%. For all the cultivars, weed coexistence the during the first 42 days after transplanting did not reduce the total bulbal weight or the average weight by bulb, being defined as the period before interference (PBI). There was no difference in the PBI extension of the onion cultivars studied.

Key words: infesting community, cultivars.

\section{INTRODUÇÃO}

A cultura da cebola, apesar de sua importância econômica e social, é considerada de grande risco ambiental devido à sua elevada utilização de insumos, pois é uma planta exigente em solos férteis, que são intensamente movimentados, necessitando de pesadas

1 Recebido para publicação em 30.8.2002 e na forma revisada em 12.12.2003.

Trabalho de graduação do primeiro autor.

2 Eng.-Agr., Mestrando em Produção Vegetal pela FCAV-UNESP, 14884-900 Jaboticabal-SP; ${ }^{3}$ Professor Titular do Departamento de Biologia Aplicada à Agropecuária, FCAV-UNESP; ${ }^{4}$ Professora Dra. do Departamento de Produção Vegetal, FCAV-UNESP.

${ }^{5}$ Eng.-Agr. Doutorando em Fitotecnia pela ESALQ-USP, Piracicaba-SP. ${ }^{6}$ Eng.-Agr., Dr., Hokko do Brasil Indústria Química e Agropecuária Ltda., Pereiras-SP. 
adubações e da freqüente aplicação de fertilizantes. Além disso, está sujeita à ação de grande número de pragas e patógenos, necessitando de freqüentes e diversificadas aplicações de pesticidas (Obara, 1991). Esse tipo de manejo do solo, aliado à baixa capacidade de sombreamento da cultura, propicia condições ideais à germinação e ao desenvolvimento de densas populações de plantas daninhas de elevada agressividade, obrigando o agricultor a adotar práticas de controle que contribuem de forma significativa para o aumento dos custos de produção e do impacto ambiental, principalmente quando o controle químico é predominante (Pitelli, 1987a).

A cultura da cebola é considerada altamente suscetível à interferência imposta pelas plantas daninhas, em virtude do seu lento crescimento inicial e da disposição ereta e forma cilindrica de suas folhas, o que proporciona baixa capacidade de sombreamento. Van Heemst (1985) verificou os efeitos da competição das plantas daninhas em 26 culturas agrícolas e listou-as na ordem decrescente de capacidade competitiva. $\mathrm{O}$ trigo foi considerado de maior capacidade e a cebola foi classificada em último lugar. Como conseqüência final da interferência das plantas daninhas, a produtividade da cebola decresce drasticamente, podendo atingir até $100 \%$ de perdas na produção de bulbos comercializáveis. Alguns valores de redução na produção comercial encontrados na literatura variam de 36 a 96\% (Paller Jr. et al., 1971; Deuber \& Forster, 1975; Leal, 1984).

Os estudos sobre a interferência das plantas daninhas em culturas agrícolas visam determinar os períodos ou as épocas que são críticas na interação cultura - comunidade infestante. Tais períodos são definidos por Pitelli \& Durigan (1984) como Período Anterior à Interferência (PAI), Período Total de Prevenção à Interferência (PTPI) e Período Crítico de Interferência (PCPI). No Brasil, esses estudos são escassos e restritos às culturas de grande interesse econômico, como o milho, a soja e o arroz inundado. Há, portanto, uma grande carência de trabalhos científicos dessa natureza, envolvendo culturas de hortaliças (Pitelli, 1987b).

Nesse contexto, este trabalho teve como objetivo estudar os efeitos de diferentes períodos de convivência de uma comunidade infestante sobre a produtividade de quatro cultivares de cebola, conduzidos no sistema de transplantio.

\section{MATERIAL E MÉTODOS}

A presente pesquisa foi realizada em campo, durante o período de abril a outubro de 2000, em área experimental da Faculdade de Ciências Agrárias e Veterinárias da UNESP, campus de Jaboticabal-SP, em Latossolo Roxo distrófico. No dia 18 de abril, foi realizada a semeadura da cebola em bandejas de poliestireno expandido com 288 cavidades, preenchidas com substrato comercial (Plantmax ${ }^{\circledR}$ ). $O$ transplantio foi realizado em linhas espaçadas de 0,3 m, mantendo-se espaço de 0,08 m entre plantas no sulco. Essa densidade proporcionou uma população de 41,7 plantas $\mathrm{m}^{-2}$. Pouco antes do transplantio, efetuado em 30 de maio, foi realizada a adubação, em quantidades equivalentes a $30 \mathrm{~kg} \mathrm{ha}^{-1}$ de nitrocálcio, $120 \mathrm{~kg} \mathrm{ha}^{-1}$ de cloreto de potássio e $90 \mathrm{~kg} \mathrm{ha}^{-1}$ de superfosfato simples. Essas quantidades foram calculadas com base na análise do solo.

Aos 25 e 50 dias após o transplantio, foram realizadas as adubações em cobertura, aplicando-se a mistura de $25 \mathrm{~kg} \mathrm{ha}^{-1}$ de nitrocálcio e $25 \mathrm{~kg} \mathrm{ha}^{-1}$ de cloreto de potássio. Para o controle preventivo de pragas e doenças, foram efetuadas pulverizações quinzenais dos fungicidas azoxystrobin ( $25 \mathrm{~g}$ de i.a. ha-1) e iprodione (750 g de i.a. ha ${ }^{-1}$ ) e do inseticida methamidophos (300 g de i.a. ha-1).

O experimento obedeceu ao delineamento experimental de blocos ao acaso, com quatro repetições. Os tratamentos foram distribuídos num esquema fatorial $4 \times 8$, em que constituíram as variáveis quatro cultivares de cebola (Mercedes, Granex 33, Superex e Serrana) e oito períodos de convivência da cultura com a comunidade de plantas daninhas $(0,14,28$, $42,56,70,84$ e 98 dias após o transplantio). O controle das plantas daninhas foi feito por meio de capinas manuais na entrelinha e monda nas proximidades da planta de cebola. Cada parcela experimental foi constituída por quatro linhas de plantio com $2,0 \mathrm{~m}$ de comprimento, perfazendo uma área de $2,4 \mathrm{~m}^{2}$, sendo $0,3 \mathrm{~m}$ das extremidades e as duas linhas externas, consideradas como bordadura. 
A comunidade infestante foi avaliada ao final de cada período de convivência, sendo coletadas todas as plantas daninhas presentes em $0,5 \mathrm{~m}^{2}$ da área útil de cada parcela, correspondendo a duas subamostras de $0,25 \mathrm{~m}^{2}$. As espécies de plantas daninhas foram identificadas, quantificadas e levadas ao laboratório, onde foram lavadas e depois secas em estufa com circulação forçada de ar a $70-80{ }^{\circ} \mathrm{C}$, por 96 horas. Após esse procedimento, foi determinada a biomassa seca da parte aérea das plantas daninhas coletadas, utilizando-se balança eletrônica com precisão de 0,01 g.

Por ocasião da colheita, foram efetuadas as avaliações da produção e da qualidade dos bulbos colhidos nas áreas úteis das parcelas. Os bulbos de cada parcela foram classificados, de acordo com o diâmetro transversal, em classe 5 (diâmetro maior que $9 \mathrm{~cm}$ ), classe 4 (diâmetro entre 7 e $9 \mathrm{~cm}$ ), classe 3 (diâmetro entre 7 e $5 \mathrm{~cm}$ ), classe 2 (diâmetro entre $5 \mathrm{e}$ $3,5 \mathrm{~cm}$ ) e refugo (diâmetro menor que $3,5 \mathrm{~cm}$ ), conforme classificação adotada pela CEAGESP* (1999). Após a classificação, os bulbos foram contados e pesados em balança eletrônica com precisão de 0,01 g. Posteriormente, foram calculadas as distribuições percentuais em cada classe de tamanho.

$\mathrm{Na}$ comunidade infestante, foram realizados estudos fitossociológicos das populações presentes e, ainda, estudos de regressão para acúmulo de biomassa seca e densidade de plantas daninhas ao final dos períodos de convivência.

Os índices fitossociológicos de constância, densidade, dominância e importância relativas foram calculados por fórmulas propostas por Mueller-Dombois \& Ellemberg (1974).

A constância relativa (Co.R.) refere-se à intensidade de ocorrência de uma espécie nos vários segmentos geográficos da comunidade. É expressa em termos de porcentagem de amostras em que indivíduos de uma espécie foram detectados, em relação ao número total de amostras efetuadas.

* CEAGESP - Companhia de Entrepostos e Armazéns Gerais do Estado de São Paulo. Comunicação pessoal (1999).
A densidade relativa (De.R.) refere-se à porcentagem de indivíduos de uma mesma espécie em relação ao total de indivíduos da comunidade.

A dominância relativa (Do.R.) refere-se à relação entre o peso da matéria seca acumulada pela espécie e o peso da matéria seca total da comunidade infestante.

A importância relativa (I.R.) é um índice complexo que envolve os três fatores anteriores, sendo calculado pelo somatório da constância, densidade e dominância relativas.

$\mathrm{Na}$ comunidade infestante, foi estudado, ainda, o indice de diversidade de ShannonWeaver (H), citado por Pinto-Coelho (2000). Esse índice é calculado por meio da seguinte fórmula:

$$
H=\sum_{i=1}^{S} p_{i} \ln p_{i}
$$

em que s é o número de espécies e $\mathrm{p}_{\mathrm{i}}$ é a proporção da amostra contendo indivíduos da espécie i.

Os dados de produção de bulbos obtidos foram submetidos à análise de variância pelo teste $\mathrm{F}$, considerando um experimento fatorial $4 \times 8$. As médias foram confrontadas pelo teste de comparação múltipla de Tukey em nível de $1 \%$ de probabilidade. O teste de Tukey é útil para separar o período de convivência que reduz significativamente o componente da produção, quando comparada com a testemunha no limpo.

\section{RESULTADOS E DISCUSSÃO}

Considerando que as áreas de olericultura são adequadas ao desenvolvimento de inúmeras populações ruderais, devido à grande disponibilidade de recursos, freqüência dos distúrbios do solo e grande desuniformidade espacial na ocupação da área (Pitelli, 1987b), pode-se considerar que ocorreu um pequeno número de espécies. As plantas daninhas presentes na comunidade infestante foram Amaranthus hybridus, Brachiaria plantaginea, Chamomila recutita, Coronopus dydimus, Cyperus rotundus, Digitaria horizontalis, Eleusine indica, Galinsoga parviflora, Gnaphalium spicatum, Lepidium virginicum, 
Nicandra physaloides, Solanum americanum e Sonchus oleraceus.

Todas as espécies presentes podem ser consideradas ruderais de acordo com os critérios de Grime (1979). As principais características desse grupo de plantas são: rápida germinação, curto ciclo de desenvolvimento, rápida produção de diásporos e elevada partição de recursos nas estruturas de reprodução. Coronopus dydimus mostrou fortes evidências desse caráter ruderal.

Na Figura 1 estão apresentadas as curvas de acúmulo de biomassa seca pelas comunidades infestantes da cultura da cebola, nos quatro cultivares. Não houve diferenças expressivas entre os acúmulos de biomassa seca obtidos em função dos diferentes cultivares. Pitelli (1987b) comenta que, devido às características morfológicas e de arquitetura das plantas de cebola, não são esperadas grandes diferenças nas capacidades de diferentes cultivares em competir com as plantas daninhas. Os acúmulos máximos observados estiveram na faixa
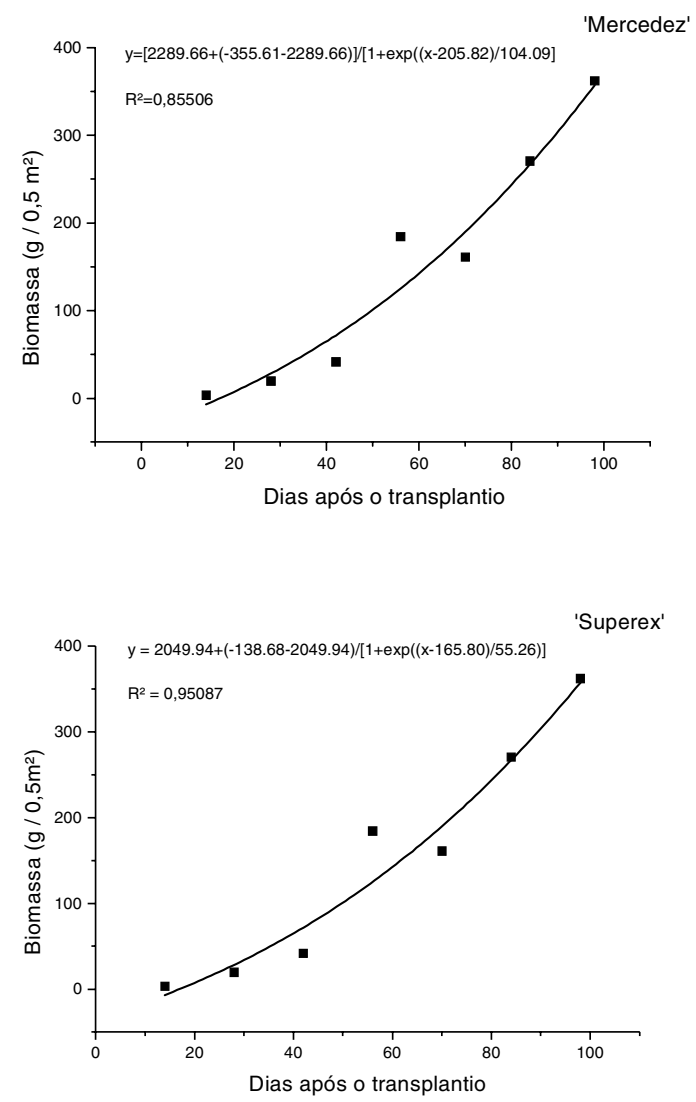

entre 350 e $400 \mathrm{~g} / 0,5 \mathrm{~m}^{2}$ para todos os cultivares.

Nos cultivares Mercedes, Granex-33 e Superex (Figura 1), as curvas de acúmulo obedeceram a tendências sigmoidais, mas com grandes componentes lineares nas faixas de valores observados. Houve tendência de aceleração do acúmulo de biomassa seca com o desenvolvimento do ciclo da cebola, especialmente a partir dos 30 dias. Esse fato é esperado, em função da baixa capacidade competitiva dessa cultura.

Na Figura 1, observa-se comportamento diferenciado na curva de tendência de acúmulo de biomassa seca pelas plantas daninhas em parcelas cultivadas com o cultivar Serrana. Esse tipo de modelo (modelo de Gaussian) pode ter sido influenciado pela ocorrência de densas populações de Galinsoga parviflora e Nicandra physaloides aos 70 dias, o que não ocorreu nas parcelas das duas datas subseqüentes, nesse cultivar.
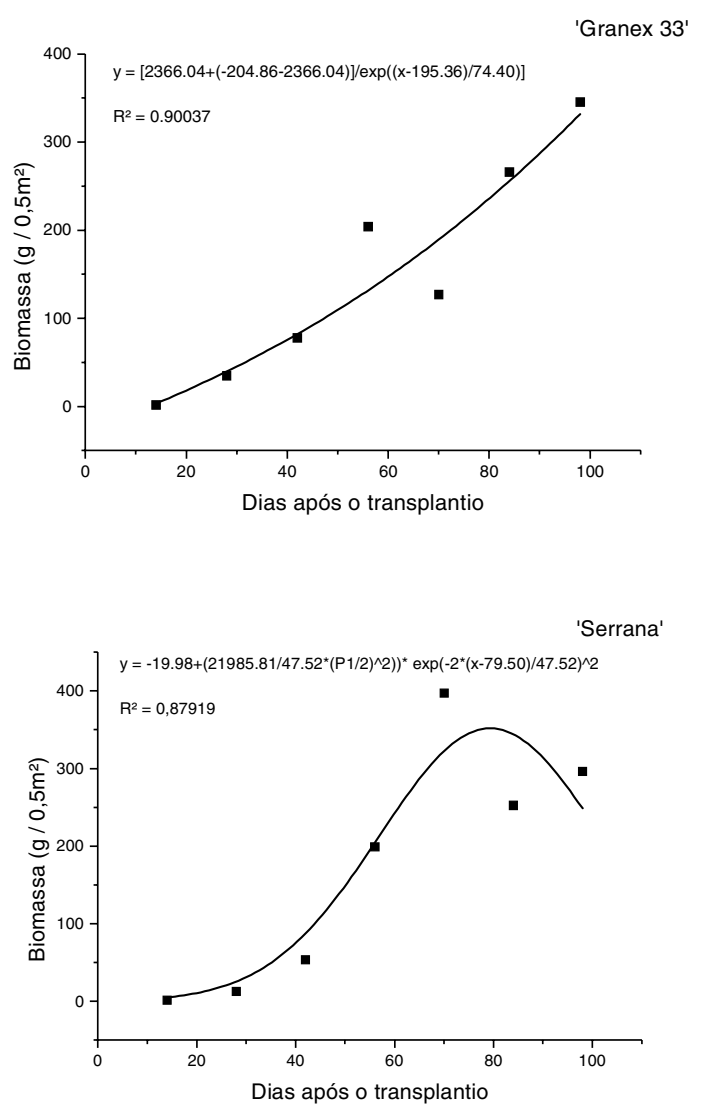

Figura 1 - Variação temporal dos valores de biomassa seca acumulada pela comunidade infestante $\left(\mathrm{g} / 0,5 \mathrm{~m}^{2}\right)$ nas parcelas cultivadas com cebola dos cultivares Mercedes, Granex 33, Superex e Serrana. FCAV-UNESP, Jaboticabal-SP, 2000. 
A densidade de plantas daninhas (Figura 2) apenas se ajustou fracamente ao modelo de Gaussian. Esse ajuste não explica satisfatoriamente a variação da densidade de indivíduos de uma comunidade infestante num campo agrícola, por considerar uma simetria entre as partes ascendente e descendente da curva. De qualquer maneira, por este modelo, há um incremento teórico do número de indivíduos da comunidade até 56 dias. As variações podem ser explicadas pela não-uniformidade do fluxo de germinação das diferentes populações. A partir desse período, houve redução da densidade de plantas, em razão do aumento na mortalidade de plantas ocasionado pelo encerramento de ciclo ou pela ação de inimigos naturais.

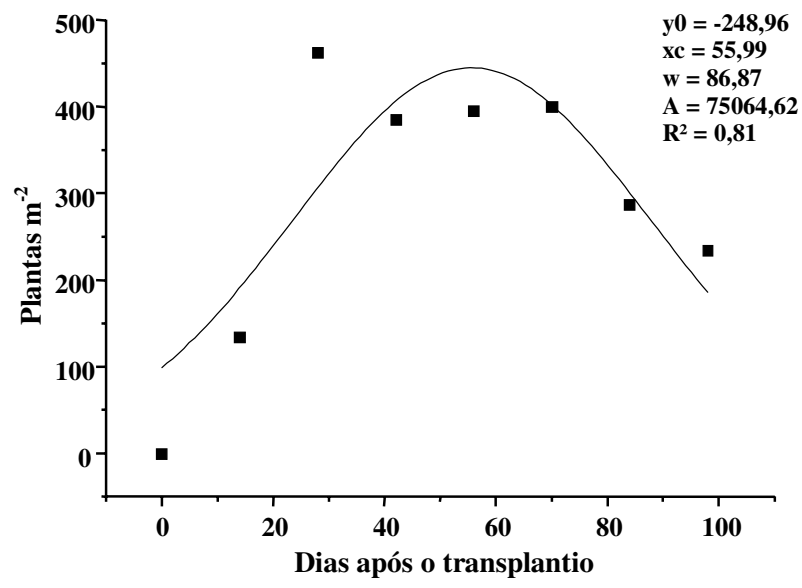

Figura 2 - Valores observados e curva estimada do número de plantas na comunidade infestante da cultura da cebola, em diferentes períodos após o transplantio. FCAV-UNESP, Jaboticabal-SP, 2000.

Nas Tabelas 1 e 2 estão apresentados os resultados referentes aos estudos fitossociológicos desenvolvidos com a comunidade infestante, nas diferentes épocas de avaliação, durante o ciclo da cebola.

Aos 14 dias após o transplantio da cebola, C. dydimus foi a população com maior representatividade numérica na comunidade infestante, embora $C$. rotundus tivesse maior destaque em termos de biomassa seca acumulada $(86,8 \%$ de dominância relativa). C. dydimus, A. hybridus e B. plantaginea são plantas de reprodução seminífera, cujas plântulas são muito pequenas em comparação com as brotações de $C$. rotundus, que emergem de tubérculos com grande quantidade de reserva. Essa característica determinou que C. rotundus apresentasse maior importância relativa da comunidade infestante aos 14 dias.

Aos 28 dias após o transplantio, o rápido crescimento das plantas de C. dydimus, constituindo uma das características ruderais da espécie (Grime, 1979), fez com que esta se tornasse a população com maior destaque, tanto em termos de densidade de indivíduos (De.R. $68,3 \%$ ) como de acúmulo de biomassa seca (Do.R. 62,5\%). Esse comportamento lhe conferiu a maior importância relativa da comunidade infestante nessa avaliação.

Aos 42 dias após o transplantio, a comunidade infestante apresentou 13 espécies, com predominância das famílias Asteraceae e Poaceae. O maior valor de importância relativa foi da população de C. dydimus, seguida de A. hybridus.

Na quarta avaliação, realizada aos 56 dias após o transplantio, não surgiram novas populações. A dominância relativa da população de C. dydimus foi de $48,2 \%$, seguida pelas populações de $C$. rotundus e de A. hybridus. Nessa mesma ordem ocorreram as importâncias relativas das principais populações.

$\mathrm{Na}$ avaliação da comunidade infestante, realizada aos 70 dias após o transplantio, C. dydimus continuou sendo a população com maiores valores de densidade, dominância e importância relativas. Em se tratando de densidade relativa, ainda se destacaram as populações de $A$. hybridus e $C$. rotundus, mas, com relação à biomassa acumulada, os destaques foram observados para A. hybridus e G. parviflora.

Aos 84 e 98 dias (última avaliação) após o transplantio da cebola, observou-se predominância de C. dydimus em termos de dominância relativa, porém foram expressivos os crescimentos das biomassas das populações de G. parviflora e A. hybridus. Esse comportamento foi verificado também na comparação da importância relativa das populações.

Os estudos fitossociológicos apresentam grandes limitações quando algumas populações estão presentes. A população de 
Tabela 1 - Valores das médias, variâncias, índices de agregação e índices fitossociológicos de constância, densidade, dominância e importância relativas das populações componentes da comunidade infestante da cultura da cebola, aos 14, 28, 42 e 56 dias após o transplantio. FCAV-UNESP, Jaboticabal-SP, 2000

\begin{tabular}{|c|c|c|c|c|c|c|c|}
\hline \multirow{2}{*}{ População } & Média & \multirow{2}{*}{ Variância } & \multirow{2}{*}{$\begin{array}{l}\text { Índice de } \\
\text { Agregação }\end{array}$} & Co.R. & De.R. & Do.R & I.R. \\
\hline & $\left(\right.$ plantas $\left.\mathrm{m}^{-2}\right)$ & & & \multicolumn{4}{|c|}{$(\%)$} \\
\hline \multicolumn{8}{|c|}{14 dias } \\
\hline AMAHY & 22,2 & 320,7 & 28,8 & 17,9 & 16,6 & 3,0 & 12,5 \\
\hline COPDI & 77,0 & $1.374,8$ & 35,7 & 35,9 & 57,4 & 9,7 & 34,3 \\
\hline CYPRO & 31,6 & 174,0 & 11,0 & 41,0 & 23,7 & 86,8 & 50,5 \\
\hline BRAPL & 3,2 & 19,9 & 12,7 & 5,1 & 2,3 & 0,6 & 2,7 \\
\hline \multicolumn{8}{|c|}{28 dias } \\
\hline AMAHY & 77,6 & 775,0 & 20,0 & 19,2 & 16,8 & 11,2 & 15,7 \\
\hline GASPA & 15,2 & 100,4 & 13,2 & 12,8 & 3,3 & 5,8 & 7,3 \\
\hline COPDI & 315,2 & $3.1458,1$ & 199,6 & 20,5 & 68,3 & 62,5 & 50,4 \\
\hline LEPVI & 8,6 & 30,9 & 7,2 & 11,5 & 1,9 & 3,5 & 5,6 \\
\hline CYPRO & 17,2 & 50,8 & 5,9 & 15,4 & 3,7 & 12,7 & 10,6 \\
\hline ELEIN & 2,6 & 12,2 & 9,8 & 1,3 & 0,5 & 0,5 & 0,8 \\
\hline NICPH & 10,8 & 95,2 & 17,7 & 10,3 & 2,3 & 1,4 & 4,7 \\
\hline BRAPL & 14,6 & 140,9 & 19,4 & 9,0 & 3,1 & 2,5 & 4,9 \\
\hline \multicolumn{8}{|c|}{42 dias } \\
\hline AMAHY & 68,6 & 381,1 & 11,1 & 13,7 & 17,8 & 20,2 & 17,2 \\
\hline GASPA & 9,8 & 23,9 & 4,9 & 12,8 & 2,5 & 10,0 & 8,5 \\
\hline GNASP & 0,6 & 1,0 & 4,0 & 0,9 & 0,1 & 0,0 & 0,3 \\
\hline COPDI & 218,2 & $2.766,2$ & 25,4 & 13,7 & 56,7 & 45,3 & 38,6 \\
\hline LEPVI & 6,6 & 9,2 & 2,8 & 10,3 & 1,7 & 2,6 & 4,9 \\
\hline Chamomila & 1,2 & 1,6 & 2,8 & 2,6 & 0,3 & 0,3 & 1,0 \\
\hline CYPRO & 35,4 & 156,1 & 8,8 & 11,1 & 9,2 & 10,1 & 10,1 \\
\hline ELEIN & 19,6 & 105,3 & 10,8 & 8,5 & 5,1 & 2,3 & 5,3 \\
\hline $\mathrm{NICPH}$ & 11,4 & 36,8 & 6,5 & 13,7 & 3,0 & 7,3 & 8,0 \\
\hline BRAPL & 6,6 & 21,3 & 6,5 & 6,0 & 1,7 & 0,6 & 2,7 \\
\hline DIGHO & 6 & 44,1 & 14,7 & 3,4 & 1,6 & 1,0 & 2,0 \\
\hline SONOL & 0,2 & 0,1 & 1,0 & 0,9 & 0,0 & 0,0 & 0,3 \\
\hline SOLAM & 1,4 & 3,3 & 4,8 & 2,6 & 0,4 & 0,2 & 1,1 \\
\hline \multicolumn{8}{|c|}{56 dias } \\
\hline AMAHY & 49,2 & 824,6 & 33,5 & 13,2 & 12,5 & 13,6 & 13,1 \\
\hline GASPA & 10,2 & 165,8 & 32,8 & 12,4 & 2,6 & 9,9 & 8,3 \\
\hline GNASP & 10,2 & 38,9 & 7,7 & 6,6 & 2,6 & 1,1 & 3,4 \\
\hline COPDI & 216,8 & $2.722,2$ & 25,1 & 12,4 & 54,9 & 48,2 & 38,5 \\
\hline LEPVI & 21,2 & 200,6 & 19,0 & 10,7 & 5,3 & 5,4 & 7,2 \\
\hline Chamomila & 0,6 & 0,2 & 0,5 & 2,5 & 0,2 & 0,1 & 0,9 \\
\hline CYPRO & 48,6 & $1.428,9$ & 58,8 & 13,2 & 12,3 & 13,7 & 13,1 \\
\hline ELEIN & 9,6 & 22,3 & 4,7 & 7,4 & 2,4 & 1,1 & 3,7 \\
\hline $\mathrm{NICPH}$ & 16,2 & 250,5 & 30,8 & 6,6 & 4,1 & 4,7 & 5,1 \\
\hline BRAPL & 10,2 & 10,2 & 2,0 & 9,9 & 2,6 & 1,5 & 4,7 \\
\hline DIGHO & 2,2 & 6,6 & 6,2 & 2,5 & 0,5 & 0,5 & 1,2 \\
\hline SONOL & 0,4 & 1,2 & 6,3 & 2,5 & 0,1 & 0,2 & 0,9 \\
\hline
\end{tabular}

AMAHY - Amaranthus hybridus; BRAPL - Brachiaria plantaginea; Chamomila - Chamomila recutita; COPDI - Coronopus dydimus; CYPRO Cyperus rotundus; DIGHO - Digitaria horizontalis; ELEIN - Eleusine indica; GASPA - Galinsoga parviflora; GNASP - Gnaphalium spicatum; LEPVI - Lepidium virginicum; NICPH - Nicandra physaloides; SOLAM - Solanum americanum; SONOL - Sonchus oleraceus. 
Períodos de interferência das plantas daninhas na ...

Tabela 2 - Valores das médias, variâncias, índices de agregação e índices fitossociológicos de constância, densidade, dominância e importância relativas das populações componentes da comunidade infestante da cultura da cebola, aos 70,84 e 98 dias após o transplantio. FCAV-UNESP, Jaboticabal-SP, 2000

\begin{tabular}{|c|c|c|c|c|c|c|c|}
\hline \multirow{2}{*}{ População } & Média & \multirow{2}{*}{ Variância } & \multirow{2}{*}{$\begin{array}{l}\text { Índice de } \\
\text { Agregação }\end{array}$} & Co.R. & De.R. & Do.R & I.R. \\
\hline & $\left(\right.$ plantas $\left.\mathrm{m}^{-2}\right)$ & & & \multicolumn{4}{|c|}{$(\%)$} \\
\hline \multicolumn{8}{|c|}{70 dias } \\
\hline AMAHY & 41,2 & 249,5 & 12,1 & 12,8 & 10,3 & 11,0 & 11,4 \\
\hline GASPA & 23,6 & 106,6 & 9,1 & 12,0 & 5,9 & 10,9 & 9,6 \\
\hline GNASP & 3,6 & 8,7 & 4,8 & 4,0 & 0,9 & 0,2 & 1,7 \\
\hline COPDI & 238,0 & $2.340,7$ & 19,7 & 12,0 & 59,6 & 65,1 & 45,5 \\
\hline LEPVI & 14,2 & 46,0 & 6,5 & 12,0 & 3,6 & 4,1 & 6,5 \\
\hline Chamomila & 1,8 & 9,1 & 10,3 & 1,6 & 0,4 & 0,2 & 0,8 \\
\hline CYPRO & 44,2 & 498,7 & 22,5 & 12,0 & 11,1 & 4,5 & 9,2 \\
\hline ELEIN & 12,0 & 110,3 & 18,4 & 8,8 & 3,0 & 0,3 & 4,0 \\
\hline $\mathrm{NICPH}$ & 12,2 & 68,3 & 11,3 & 8,8 & 3,0 & 3,2 & 5,0 \\
\hline BRAPL & 1,4 & 1,6 & 2,3 & 4,0 & 0,3 & 0,0 & 1,5 \\
\hline DIGHO & 5,2 & 5,5 & 2,1 & 8,0 & 1,3 & 0,2 & 3,2 \\
\hline SONOL & 0,2 & 0,1 & 1,0 & 0,8 & 0,0 & 0,1 & 0,3 \\
\hline SOLAM & 2,2 & 6,5 & 6,1 & 3,2 & 0,5 & 0,3 & 1,4 \\
\hline \multicolumn{8}{|c|}{84 dias } \\
\hline AMAHY & 54,4 & 750,7 & 27,6 & 12,0 & 18,9 & 28,1 & 19,7 \\
\hline GASPA & 21,0 & 53,1 & 5,1 & 13,7 & 7,3 & 10,5 & 10,5 \\
\hline GNASP & 3,2 & 10,1 & 6,5 & 3,4 & 1,1 & 0,3 & 1,6 \\
\hline COPDI & 155,8 & $1.433,6$ & 18,4 & 13,7 & 54,2 & 44,5 & 37,5 \\
\hline LEPVI & 10,8 & 44,8 & 8,3 & 11,1 & 3,7 & 5,9 & 6,9 \\
\hline Chamomila & 0,2 & 0,3 & 2,0 & 0,9 & 0,1 & 0,2 & 0,4 \\
\hline CYPRO & 19,2 & 108,9 & 11,3 & 12,0 & 6,7 & 1,4 & 6,7 \\
\hline ELEIN & 4,0 & 5,3 & 2,7 & 6,8 & 1,4 & 0,4 & 2,9 \\
\hline NICPH & 8,6 & 51,5 & 12,1 & 9,4 & 3,0 & 6,4 & 6,2 \\
\hline BRAPL & 0,8 & 1,6 & 4,2 & 1,7 & 0,3 & 0,0 & 0,7 \\
\hline DIGHO & 1,8 & 2,5 & 2,9 & 4,3 & 0,6 & 0,1 & 1,7 \\
\hline SONOL & 0,6 & 0,3 & 1,3 & 2,6 & 0,2 & 0,3 & 1,0 \\
\hline SOLAM & 7,2 & 64,8 & 18,2 & 8,5 & 2,5 & 1,8 & 4,3 \\
\hline \multicolumn{8}{|c|}{98 dias } \\
\hline AMAHY & 43,8 & 156,0 & 7,1 & 13,5 & 18,7 & 33,9 & 22,0 \\
\hline GASPA & 12,2 & 16,9 & 2,8 & 13,5 & 5,2 & 13,3 & 10,6 \\
\hline GNASP & 1,2 & 1,1 & 1,7 & 4,8 & 0,5 & 0,1 & 1,8 \\
\hline COPDI & 90,2 & 504,9 & 11,2 & 15,4 & 38,5 & 18,2 & 24,0 \\
\hline LEPVI & 18,4 & 171,8 & 18,7 & 9,6 & 7,8 & 18,2 & 11,9 \\
\hline Chamomila & 0,2 & 0,1 & 0,9 & 1,9 & 0,1 & 0,2 & 0,7 \\
\hline CYPRO & 32,4 & 120,3 & 7,4 & 15,4 & 13,8 & 1,8 & 10,3 \\
\hline ELEIN & 17,6 & 299,0 & 33,9 & 6,7 & 7,5 & 0,2 & 4,8 \\
\hline NICPH & 16,0 & 445,5 & 55,7 & 9,6 & 6,8 & 12,8 & 9,7 \\
\hline BRAPL & 0,2 & 0,1 & 1,0 & 1,0 & 0,1 & 0,0 & 0,3 \\
\hline DIGHO & 0,8 & 0,5 & 1,4 & 3,8 & 0,3 & 0,1 & 1,4 \\
\hline SONOL & 0,2 & 0,1 & 1,0 & 1,0 & 0,1 & 0,2 & 0,4 \\
\hline SOLAM & 1,2 & 1,9 & 3,0 & 3,8 & 0,5 & 1,1 & 1,8 \\
\hline
\end{tabular}

AMAHY - Amaranthus hybridus; BRAPL - Brachiaria plantaginea; Chamomila - Chamomila recutita; COPDI - Coronopus dydimus; CYPRO Cyperus rotundus; DIGHO - Digitaria horizontalis; ELEIN - Eleusine indica; GASPA - Galinsoga parviflora; GNASP - Gnaphalium spicatum; LEPVI - Lepidium virginicum; NICPH - Nicandra physaloides; SOLAM - Solanum americanum; SONOL - Sonchus oleraceus. 
C. rotundus é um exemplo na comunidade vegetal em análise. A densidade relativa superestima a participação dos indivíduos de C. rotundus na comunidade, pois considera cada manifestação epígea como uma planta. Por outro lado, apenas a biomassa epígea das populações é considerada para os cálculos da dominância relativa, desconsiderando a grande proporção de biomassa subterrânea. Na literatura consultada não foi encontrado qualquer estudo que avaliasse o balanço entre a superestimativa da participação numérica de C. rotundus na comunidade e a subestimativa da participação da biomassa acumulada.

$O$ índice de diversidade de ShannonWeaver, citado por Pinto-Coelho (2000), considera o número de populações presentes e a participação percentual de cada população na comunidade. Neste estudo, o índice foi calculado considerando-se as participações das populações em termos de densidade relativa, dominância relativa e importância relativa. Os resultados estão apresentados na Figura 3. O índice de Shannon-Weaver é máximo quando todas as populações têm a mesma participação na comunidade, ou seja, a equitabilidade das populações é máxima. O valor máximo teórico cresceu com a emergência de novas populações até os 42 dias, após o qual nenhuma nova espécie foi detectada nas amostragens efetuadas. Para as três formas de participação das populações eleitas para o estudo, houve incremento do índice de diversidade até os 42 dias após o transplantio da planta cultivada; posteriormente ocorreu relativa estabilidade dos valores e novo incremento na fase final do ciclo da

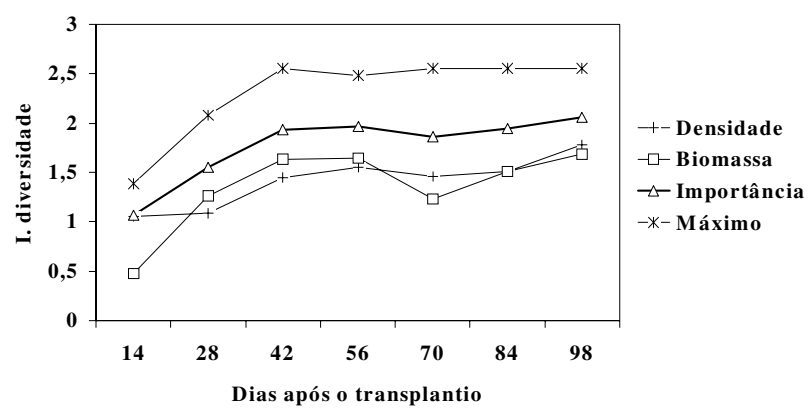

Figura 3 - Valores do índice de diversidade de ShannonWeaver da comunidade infestante da cultura da cebola em diferentes épocas, considerando a densidade de indivíduos, a biomassa acumulada e a importância relativa das populações. FCAV-UNESP, Jaboticabal-SP, 2000. cebola. Houve maior estabilidade no índice de diversidade quando se considerou a participação numérica das populações. Na primeira amostragem houve pequena equitabilidade no indice de diversidade, considerando os valores de biomassa acumulada, devido à grande disparidade entre os valores da população de C. rotundus e os das biomassas das plântulas de espécies anuais.

Com o tempo, passou a haver equilíbrio entre as diversidades numéricas e de biomassa das populações na comunidade. De qualquer maneira, ficou evidente que o parâmetro fitossociológico de importância relativa reflete as participações das populações na comunidade infestante de forma mais equilibrada, pois seus valores sempre sobrepujaram os calculados com as outras modalidades de participação e foram mais próximos da equitabilidade ideal (índice de diversidade máximo). Esse comportamento é possível porque a importância relativa é um índice complexo, que considera a densidade de indivíduos, a biomassa acumulada e a distribuição geográfica das populações na área experimental.

Na Tabela 3 estão apresentados os valores médios da produção de bulbos de cebola, do número de bulbos por metro quadrado e do peso de bulbos, considerando as variáveis principais e os resultados das análises de variância correspondentes. Não foi estatisticamente detectada qualquer interação entre os cultivares testados e os diferentes períodos de convivência com as plantas daninhas a que foram submetidos. Esses resultados sugerem que os cultivares de cebola responderam de modo similar aos períodos de convivência de plantas daninhas testados. Pitelli (1987b) comenta que, em razão das características morfológicas e da arquitetura das plantas de cebola, as diferenças entre os cultivares dificilmente proporcionam impactos suficientes sobre o crescimento da comunidade infestante, a ponto de constituir uma vantagem competitiva e permitir maior produtividade do cultivar quando em convivência com as plantas daninhas.

Assim, apenas foram comparadas as médias entre os cultivares e as médias entre os períodos de convivência com as plantas daninhas. Os maiores pesos totais de bulbos foram observados nos cultivares Mercedes e 
Tabela 3 - Produção total de bulbos para quatro cultivares submetidos a oito períodos de convivência de plantas daninhas na cultura da cebola transplantada. FCAV-UNESP. Jaboticabal-SP, 2000

\begin{tabular}{|c|c|c|c|}
\hline Variável principal & $\begin{array}{l}\text { Peso total de } \\
\text { bulbos }\left(\mathrm{g} \mathrm{m}^{-2}\right)\end{array}$ & $\begin{array}{c}\text { Número médio } \\
\text { de bulbos (bulbos } \mathrm{m}^{-2} \text { ) }\end{array}$ & $\begin{array}{l}\text { Peso médio de } \\
\text { bulbos }(\mathrm{g})\end{array}$ \\
\hline \multicolumn{4}{|c|}{ Cultivares (cv) } \\
\hline Mercedez & $2.905,13 \mathrm{a}^{\frac{1 /}{}}$ & 5,4 a & 92,37 a \\
\hline Granex-33 & $2.644,29 \mathrm{ab}$ & $4,9 \mathrm{bc}$ & 93,77 a \\
\hline Superex & $2.405,04 \mathrm{~b}$ & $4,8 \mathrm{c}$ & $83,12 \mathrm{ab}$ \\
\hline Serrana & $2.332,04 \mathrm{~b}$ & $5,3 \mathrm{ab}$ & $74,95 \mathrm{~b}$ \\
\hline \multicolumn{4}{|c|}{ Períodos $(\mathrm{p})$} \\
\hline 00 dias & $4.058,55 \mathrm{a}$ & 5,6 a & 132,25 a \\
\hline $00-14$ dias & $4.255,52$ a & 5,6 a & 136,66 a \\
\hline $00-28$ dias & $3.516,96 \mathrm{ab}$ & 5,6 a & $114,78 \mathrm{ab}$ \\
\hline $00-42$ dias & $3.746,16 \mathrm{ab}$ & 5,5 a & 125,75 a \\
\hline $00-56$ dias & $3.009,28 \mathrm{~b}$ & 5,5 a & $97,54 \quad b$ \\
\hline $00-70$ dias & $1.218,39 \mathrm{c}$ & $5,1 \quad a b$ & $44,77 \mathrm{c}$ \\
\hline $00-84$ dias & $582,35 \mathrm{~cd}$ & $4,6 \mathrm{~b}$ & $24,51 \mathrm{~cd}$ \\
\hline $00-98$ dias & $185,77 \mathrm{~d}$ & $3,5 \mathrm{c}$ & $12,06 \mathrm{~d}$ \\
\hline \multicolumn{4}{|c|}{ Análise de variância } \\
\hline $\mathrm{F}_{\mathrm{cv}}$ & $3,91 *$ & $5,15 * *$ & $5,08 * *$ \\
\hline $\mathrm{F}_{\mathrm{p}}$ & $78,99 * *$ & $18,18 * *$ & $85,77 * *$ \\
\hline $\mathrm{F}_{\mathrm{cv} \times \mathrm{p}}$ & $0,97 \mathrm{~ns}$ & $1,04 \mathrm{~ns}$ & $1,28 \mathrm{~ns}$ \\
\hline $\mathrm{DMS}_{\mathrm{cv}}$ & $485,4591 \mathrm{~g} \mathrm{~m}^{-2}$ & 0,4592 bulbos $\mathrm{m}^{-2}$ & $14,4236 \mathrm{~g}$ \\
\hline $\mathrm{DMS}_{\mathrm{p}}$ & $812,3254 \mathrm{~g} \mathrm{~m}^{-2}$ & 0,7683 bulbos $\mathrm{m}^{-2}$ & $24,1352 \mathrm{~g}$ \\
\hline $\mathrm{CV}$ & $28,8 \%$ & $13,72 \%$ & $25,59 \%$ \\
\hline
\end{tabular}

${ }^{1 /}$ Médias seguidas por mesma letra na coluna não diferem entre si pelo teste de Tukey $(p>0,05)$.

* significativo a $5 \%$ pelo teste $\mathrm{Fe}$ ** significativo a $1 \%$ pelo teste $\mathrm{F}$.

Granex 33. Os cultivares Mercedes e Serrana produziram as maiores quantidades de bulbos por unidade de área. O cultivar Mercedes apresentou elevada produção de cebola, em decorrência do elevado número e peso médio de bulbos. Em contraste, no cultivar Serrana, apesar do elevado número, os bulbos foram de pequeno tamanho médio, resultando em uma menor produtividade. O cultivar Granex 33, com elevado peso médio de bulbos, apresentou pequeno número de bulbos por unidade de área.

Pitelli (1987b) destaca que há um efeito múltiplo da interferência das plantas daninhas na produção de cebola: redução do peso da produção e redução da porcentagem de bulbos comercializáveis. Esse tipo de interação pode ser observado na Figura 4, em que fica claro que a porcentagem de bulbos menores cresce à medida que o período de convivência é incrementado.
Considerando a porcentagem de número de bulbos em diferentes classes de tamanho (Figura 4), observa-se que até 56 dias a maior parte dos bulbos esteve na classe 3 . Os locados nas classes 5 e refugo foram minoria. À medida que os períodos de convivência foram aumentados (acima de 56 dias), houve drástico aumento da porcentagem de bulbos refugo e rápidas reduções dos bulbos das classes 3 e 4 . A porcentagem de bulbos da classe 2 foi aumentada no período de convivência de 70 dias. Os períodos de convivência que proporcionaram intensas alterações das porcentagens de peso dos bulbos nas diferentes classes de tamanho foram de 70, 84 e 98 dias, a exemplo do que havia ocorrido com a porcentagem numérica (Figura 4). A partir de 56 dias de convivência houve intensa redução das porcentagens de bulbos das classes 3,4 e 5 e aumento das porcentagens de bulbos das classes 2 e refugo. 

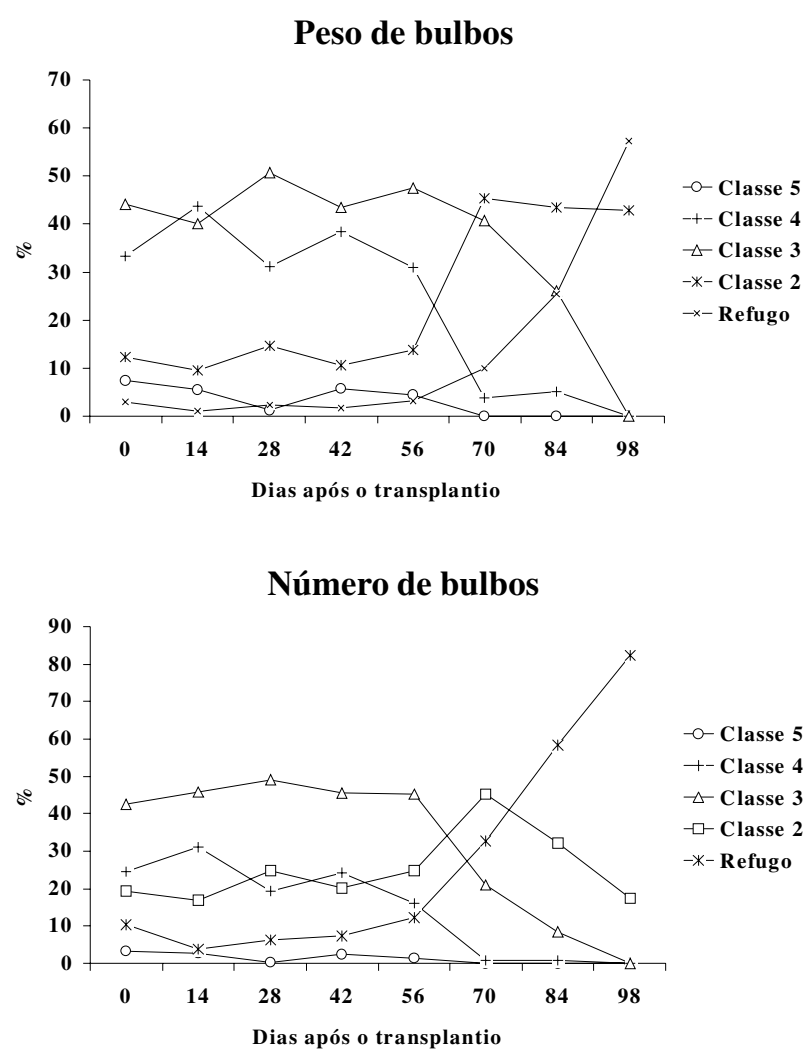

Figura 4 - Distribuição percentual do peso e número de bulbos nas diferentes classificações comerciais (CEAGESP) na produção de quatro cultivares de cebola submetidos a diferentes períodos de convivência com as plantas daninhas (média de quatro cultivares). FCAV-UNESP, JaboticabalSP, 2000.

Os efeitos dos períodos de convivência apresentaram resultados diferentes para os três componentes da produção analisados (Tabela 3). O teste de Tukey é útil para separar o período de convivência que reduz significativamente o componente da produção, quando comparado com a testemunha no limpo. O número médio de bulbos apenas foi reduzido por períodos de convivência de 84 e 98 dias. $\mathrm{O}$ peso médio foi reduzido por períodos de convivência de 56 dias ou mais. A produção total de bulbos que contempla a interação ponderada dos dois componentes anteriores também teve redução significativa com períodos de 42 dias ou mais de convivência com a comunidade infestante. Assim, o período anterior para cultura da cebola transplantada foi o de 42 dias. A convivência com as plantas daninhas durante os primeiros 98 dias reduziu a produtividade da cebola em $95 \%$ e o peso médio de bulbos em 91\%, considerando-se a média dos quatro cultivares.

\section{LITERATURA CITADA}

DEUBER, R.; FORSTER, R. Competição mato x cebola. Campinas: Instituto Agronômico do Estado de São Paulo, 1975. 21 p. (Boletim Técnico, 22).

GRIME, J. P. Estrategias de adapatación de las plantas y procesos que controlan la Vegetación. Mexico, D.F.: Noriega. 1979. p. 79-87.

Van HEEMST, H. D. J. The influence of weed competition on crop yield. Agric. Syst., v. 18, n. 2, p. 81-93, 1985.

LEAL, F. R. Efeitos da profundidade e densidade de semeadura direta com controle químico em pósemergência das plantas daninhas na produção de cebola (Allium cepa L.). 1984. 85 f. Dissertação (Mestrado em Agronomia) - Universidade Estadual Paulista, Jaboticabal, 1984.

MUELLER-DOMBOIS, D.; ELLEMBERG, H. Aims and methods of vegetation ecology. New York: Willey \& Sons, 1974. $547 \mathrm{p}$.

OBARA, S. Y. Efeitos da época e extensão do período de convivência das plantas daninhas sobre a produção da cultura da cebola (Allium cepa L.). 1991. $89 \mathrm{f}$. Monografia (Trabalho de Graduação em Agronomia) Universidade Estadual Paulista, Jaboticabal, 1991.

PALLER JR, E. C. et al. Duration of weed competition and weed control and yield in transplantion onions. Philippine Agricult., v. 55, n. 5-6, p. 221-224, 1971.

PINTO-COELHO, R. M. Fundamentos em ecologia. Porto Alegre: Artes Médicas Sul, 2000. p. 87-88.

PITELLI, R. A. Competição e controle de plantas daninhas em áreas agrícolas. Série Técn. IPEF, v. 4, n. 12, p. 1-24, 1987a.

PITELLI, R. A. Efeitos de períodos de convivência e de controle das plantas daninhas no crescimento, nutrição mineral, e produtividade da cultura da cebola (Allium cepa L.). 1987b. 140 f. Tese (Livre Docência em Ecologia) - Universidade Estadual Paulista, Jaboticabal, 1987.

PITELLI, R. A.; DURIGAN, J. C. Terminologia para períodos críticos de controle e de convivência das plantas daninhas em culturas anuais e bianuais. In: CONGRESSO BRASILEIRO DE HERBICIDAS E PLANTAS DANINHAS, 15., 1984, Belo Horizonte. Resumos... Belo Horizonte: 1984. p. 37. 